\title{
More than meets the naked eye: an unusual psoriatic arthritis mimicry and the important role of dermoscopic examination
}

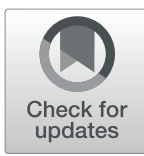

Lim Jo Anne ${ }^{1,2}$, Mohd Jazman Che Rahim ${ }^{1,2^{*}}$, Wan Syamimee Wan Ghazali ${ }^{1,2}$, Wan Aireene Wan Ahmed ${ }^{1,2}$ and Seoparjoo Azmel Mohd Isa,2

\begin{abstract}
Background: Psoriatic arthritis (PsA) can manifest in various forms. This includes mimicry of other diseases. We describe an unusual mimicry of PsA.

Case presentation: We report a case of a middle-aged lady who presented with severe pain and morning stiffness over the small joints of the left hand for 3 months and painless deformity of the affected joints 1 year before. She was under treatment for pruritic rash over her ankles and knees for the past 1 year as well. Physical examination revealed a fixed flexion deformity, swelling and tenderness of the left ring and little fingers' distal interphalangeal (DIP) joints. Left hand radiograph showed sclerotic joint margin, narrowed joint space and marginal osteophytes of the affected DIP joints. Dermoscopic examination showed red- violaceous, flat-topped papules and plaques with minimal scales on both ankles; hyperpigmented scaly plaques over both knees and vertical fingernail ridges. Serum autoimmune screening and inflammatory markers were unremarkable. Left ankle skin biopsy showed features consistent of psoriasis. PsA was diagnosed. Weekly titrated oral methotrexate and topical steroid were started. The patient showed significant improvement after 1 month of treatment.

Conclusion: PsA is a great mimicker. Dermoscopy is an accessible and valuable tool to assess skin lesions in greater detail. Clinicians should be aware of coexisting diseases or misdiagnosis when patients do not respond to treatment.
\end{abstract}

Keywords: Psoriatic arthropathy, Psoriatic arthritis, psoriasis, Lichen planus, Hand osteoarthritis, Heberden nodes

\section{Background}

In Malaysia, psoriasis commonly manifests in chronic plaque form (85.1\%) [1]. Psoriatic arthropathy is seen in $13.7 \%$ of reported cases. Psoriasis and psoriatic arthritis (PsA) are known to manifest in various forms. It may coexist or mimic other diseases such as chronic eczema, seborrheic dermatitis, onychomycosis, lichen planus and nodular prurigo, to name a few. PsA patients are at risk of irreversible joints damage, cardiovascular disease and

\footnotetext{
* Correspondence: drjazman@usm.my

'School of Medical Sciences, Universiti Sains Malaysia Health Campus, Kubang Kerian, 16150 Kota Bharu, Kelantan, Malaysia

${ }^{2}$ Hospital Universiti Sains Malaysia, Kubang Kerian, 16150 Kota Bharu, Kelantan, Malaysia
}

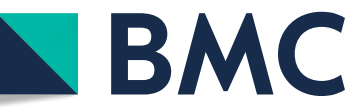

(c) The Author(s). 2021 Open Access This article is licensed under a Creative Commons Attribution 4.0 International License, which permits use, sharing, adaptation, distribution and reproduction in any medium or format, as long as you give appropriate credit to the original author(s) and the source, provide a link to the Creative Commons licence, and indicate if changes were made. The images or other third party material in this article are included in the article's Creative Commons licence, unless indicated otherwise in a credit line to the material. If material is not included in the article's Creative Commons licence and your intended use is not permitted by statutory regulation or exceeds the permitted use, you will need to obtain permission directly from the copyright holder. To view a copy of this licence, visit http://creativecommons.org/licenses/by/4.0/ The Creative Commons Public Domain Dedication waiver (http://creativecommons.org/publicdomain/zero/1.0/) applies to the data made available in this article, unless otherwise stated in a credit line to the data. 
painlessly deformed 1 year earlier and had sought medical attention. The attending general practitioners had diagnosed her as having hand osteoarthritis. There was no history of trauma, fever, hair loss or oral ulcers. She had no known prior medical illnesses. There was no family history of hand osteoarthritis or any other skin or joint diseases. There was no personal or family history of atopic eczema, asthma, allergic rhinitis and allergic conjunctivitis.

The patient also noticed multiple pruritic skin rashes over both ankles and knees for the last 1 year. According to her, the rashes were hardly scaly. She was diagnosed with lichen planus by her general practitioners. However, treatment with topical agents was to no avail.

Physical examination revealed deformity of the distal interphalangeal (DIP) joints of the left ring and little fingers. There was fixed flexion of both joints. The little finger's distal phalanx was curved inward (Fig. 1a). The joints were swollen, erythematous and tender on palpation. Range of motion was also limited due to pain. Left hand radiograph showed abnormalities at the DIP joints of the ring and little fingers (Fig. 2). Both appeared irregular with sclerotic joint margin, narrowed joint space and marginal osteophytes.

Her blood investigations showed normal white cell counts $\left(7.42 \times 10^{9} / \mathrm{L}\right)$; slightly elevated erythrocyte sedimentation rate (ESR) $(22 \mathrm{~mm} /$ hour; normal $1-20 \mathrm{~mm} /$ hour); antinuclear antibody (ANA), rheumatoid factor (RF) and anticyclic citrullinated protein antibody (ACCP A) were all negatives. The other blood cell counts, renal and liver profiles were normal.
There were multiple red-violaceous, flat-topped papules and plaques with minimal scales on the ankles (left more than right) and superficial excoriation (Fig. 1b). There were also hyperpigmented scaly plaques over both knees (Fig. 1c) and vertical ridges on her fingernails (Fig. 1d). Oral examination showed normal dentition with no mucosal streaks, erosion or ulcers. The rest of the skin, scalp and other systems examinations were unremarkable.

Dermoscopic examination using DermLite DL4 (3Gen Inc., San Juan Capistrano, 92,675, America) revealed dermoscopic Auspitz sign over a light red background, minimal white scales with a regularly distributed dotted blood vessel (Fig. 3). Punch biopsy of the skin lesion on the left ankle (Fig. 4) showed parakeratosis at the surface of the epidermis with elongation of the rete ridges; spongiosis of the epidermal layer and small capillaries proliferation seen in the papillary dermis with surrounding mixture of inflammatory cells, predominantly lymphocytes. These findings are consistent with psoriasis.

We diagnosed her as having psoriatic arthritis (PsA). Treatment consisted of weekly oral methotrexate $7.5 \mathrm{mg}$ titrated up to $15 \mathrm{mg}$ with folic acid supplement and topical betamethasone valerate cream $0.5 \%$. Her skin rash (Fig. 5) and joint pain had improved markedly after 4 weeks of treatment.

\section{Discussion and conclusion}

Several diseases share similar clinical features with psoriasis. The commonest ones that can easily mimic psoriatic plaque over the lower legs are chronic eczema, nodular prurigo and lichen planus. Patients with chronic

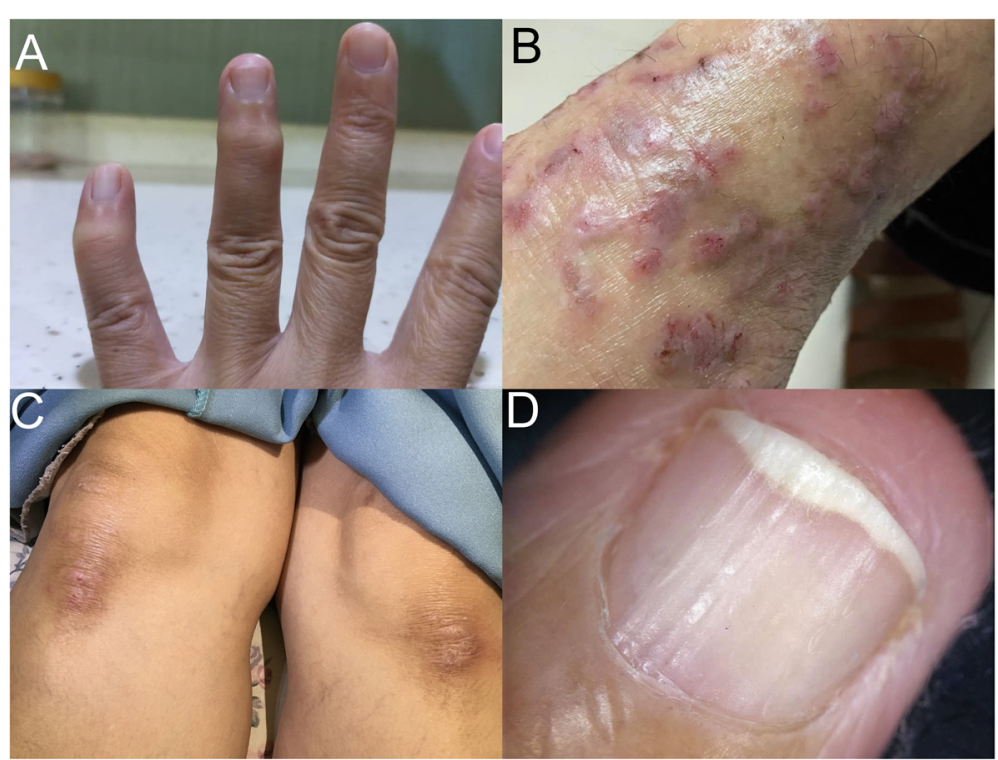

Fig. 1 a Fixed flexion and nodules of DIPJ of ring and little fingers. Inward curvature of the little finger's distal phalanx. $\mathbf{b}$ Left ankle. Multiple redviolaceous, flat-topped papules and plaques with minimal scales on the ankles and superficial excoriation. $\mathbf{c}$ Hyperpigmented scaly plaques over bilateral knee. $\mathbf{d}$ Vertical ridges on nail 


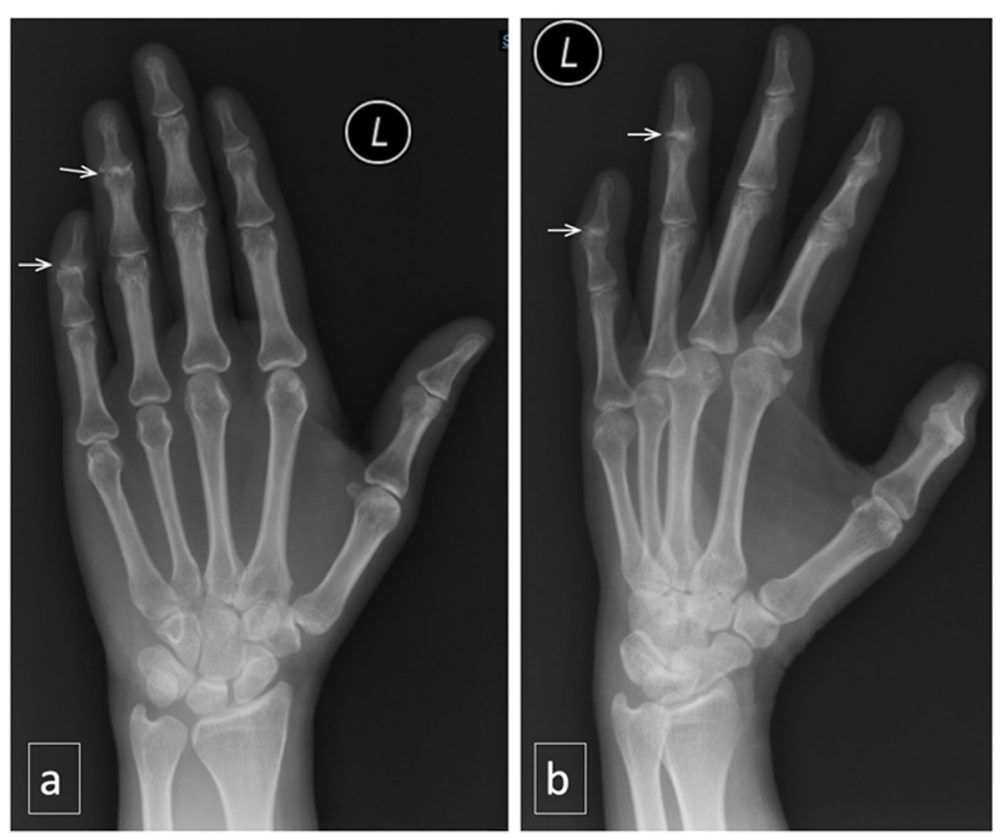

Fig. 2 X-ray of left hand in AP (a) and oblique view (b) show abnormalities of the 4th and 5th distal interphalangeal (DIP) joints. They appear irregular with sclerotic joint margin, narrowed joint space and marginal osteophytes

eczema tend to have personal or family history of atopy, asthma, allergic rhinitis, allergic conjunctivitis or potential allergen or irritant [3]. Dermoscopy of chronic eczema may present with red dots, yellow serocrust, focal dull white scales and vessels in clusters [4]. Histological findings in chronic eczema are nonspecific. These include spongiosis, intraepidermal vesicles, lymphocytic exocytosis [5].

For nodular prurigo, the itch is usually intense for days on end. The rashes are warty and crusted. Dermoscopy may reveal "white starburst pattern". Histological examination shows increase in nerve fibre ending with a negative direct immunofluorescence staining [6].

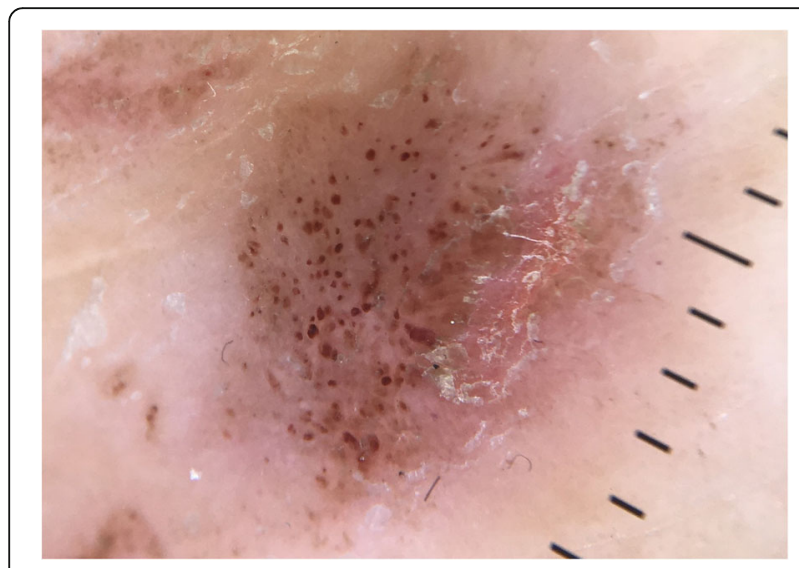

Fig. 3 Dermoscopic examination of left ankle. Dermoscopic Auspitz sign. (polarized mode, 10x magnification)
For lichen planus, $50 \%$ of patients would have mucosa involvement and $10 \%$ will have nails involvement [7]. Wickham striae can be seen clinically or dermoscopically [8]. Histological findings include immunoglobulin deposition over the epidermal basal region from direct immunofluorescent stain.

Pruritus affects $64-97 \%$ of psoriasis patients [9]. The likely mechanism is neurogenic inflammation; a combination of abnormally expressed neuropeptides, increased innervation and peripheral opioid system dysfunction [10]. Treatment relies upon resolution of the psoriatic skin lesions, either with topical medications in most cases or systemic drugs in extensive or extra-cutaneous involvement.

Our case highlights the importance of distinguishing psoriasis from other skin disorders especially lichen planus despite obvious symptoms (severe pruritus) and clinical appearance (red-violaceous, flat-topped papules and plaques with minimal scales on ankles and knees). A dermoscopic examination of the skin lesion and nail changes may give some clue, which in our case, pointed towards psoriasis (dermoscopic Auspitz sign, light red background, white scales with a regularly distributed dotted blood vesse; nail ridges). However, other pruritic lesions may present with Auspitz sign [11].

Nail ridges are not specific for psoriasis. Psoriatic nail dystrophy can present as pitting, leukonychia, onycholysis, subungual hyperkeratosis, lines or ridges, nail plate crumbling and splinter hemorrhage [12]. Lichen planus nails involvement may present as nail plate thinning, 


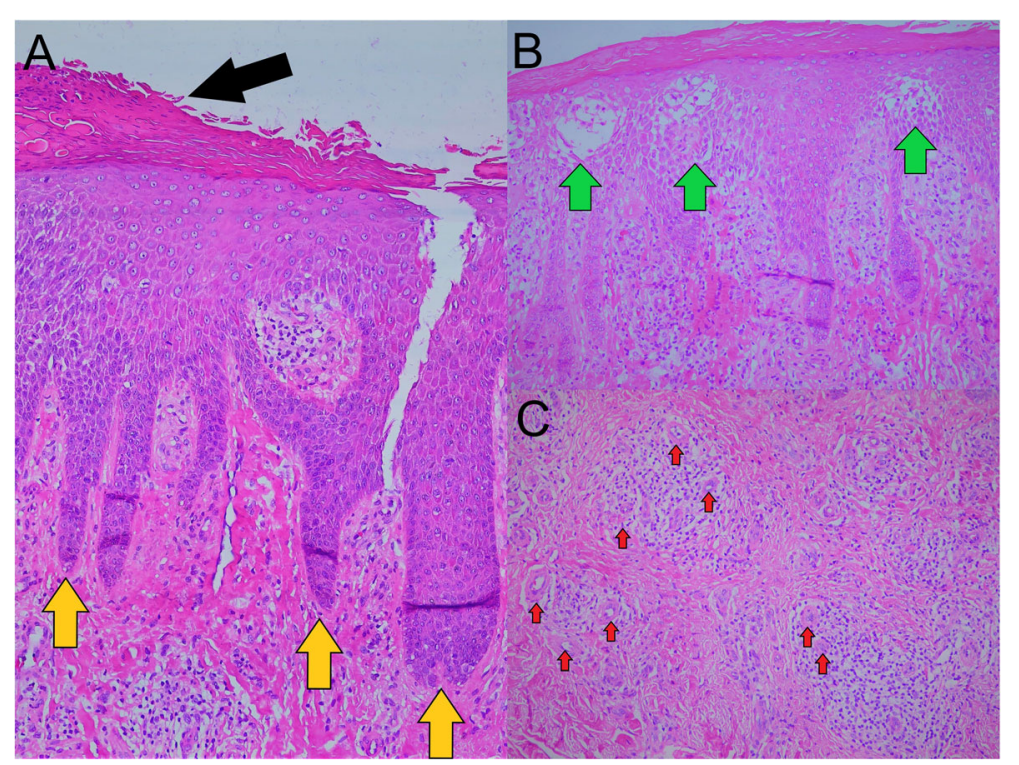

Fig. 4 a Parakeratosis (black arrow) at the surface of the epidermis with elongation of the rete ridges (yellow arrow). b Spongiosis of the epidermal layer (green arrow). c Small capillaries proliferation (red arrow) with surrounding mixture of inflammatory cells, predominantly lymphocytes. (H\&E stain, 40x)

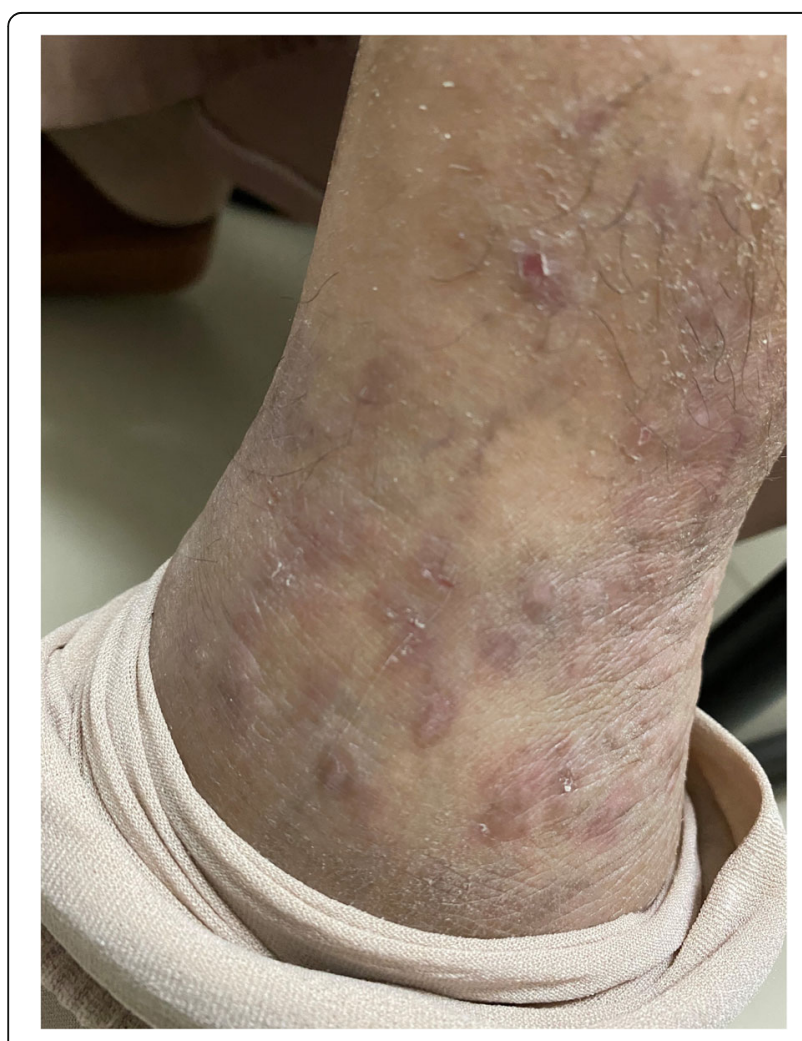

Fig. 5 Left ankle appearance 1 month after treatment grooves or ridges, nail darkening, nail thickening, onycholysis, pterygium and anonychia [13]. Other causes of vertical nail ridges include eczema, elderly, and nutritional deficiency [14].

Hand osteoarthritis (HOA) is common in female patients aged 40 years or older with positive family history. Joint pain usually occurs upon usage and morning/inactivity stiffness is usually mild [15]. Heberden nodes develop years after recurrent joint pain and swelling. PsA in its early course may have similar radiological appearance as HOA as seen in this case.

The occurrence of distal IPJ arthropathy; the absence of joint pain preceding the DIPJ deformity and Heberden nodes formation; the presence of resting joints pain, early morning joints stiffness, skin rash and nail changes added further credence to our suspicion of PsA. Ultimately, we confirmed the diagnosis with skin biopsy findings and clinical improvement with oral methotrexate and topical steroid. The rapidity of the hand joints deformity in our case indicates a very aggressive disease.

Psoriasis and lichen planus share some common features such as a red and scaly look. However, both have different pathology and distinct management. There are few reports of psoriasis and lichen planus coexistence [16]. There are also cases of lichen planus mimicking psoriasis [17]. However, case reports and pictures on psoriasis mimicking lichen planus are scarce.

To the best of our knowledge, this clinical mimicry has never been documented, especially among Asians. Our case also demonstrates the challenges of relying on history and gross physical examination alone for final 
identification of lichen planus versus psoriasis. It is important to remind clinicians of this association to avoid misdiagnosis and delay in appropriate treatment.

Non-invasive and accessible dermoscopic examination has proved to be a valuable tool in diagnosing such conditions [18]. Therefore, clinicians who frequently encounter skin diseases need to be acquainted with this important diagnostic tool. PsA may have clinical presentations that mimic other diseases or coexist with them. When response to treatment deviates from its expected course, clinicians should consider coexisting diseases and misdiagnosis.

\section{Abbreviations}

PSA: Psoriatic arthritis; DIP: Distal interphalangeal; ESR: Erythrocyte sedimentation rate; ANA: Antinuclear antibody; RF: Rheumatoid factor; ACCPA: Anticyclic citrullinated protein antibody; HOA: Hand osteoarthritis

\section{Acknowledgements}

We would like to thank the Director of Hospital Universiti Sains Malaysia for allowing us to publish this case report.

\section{Authors' contributions}

MJCR and LJA managed the patient. MJCR and LJA prepared the draft manuscript. WSWG, WAWA and SAMI edited and approved the final manuscript. The author(s) read and approved the final manuscript.

\section{Funding}

No funding

\section{Availability of data and materials}

Not applicable. All data generated or analysed during this study are included in this published article.

\section{Ethics approval and consent to participate}

Ethical approval was not sought for the present case report because it is not required as per university guideline. This study was completed in accordance with the Helsinki Declaration.

\section{Consent for publication}

Written informed consent was obtained from the patient for publication of this case report and the accompanying images. Copy of the consent is available for review.

\section{Competing interests}

The authors declared no potential conflicts of interest with respect to the research, authorship, and/or publication of this article.

Received: 1 December 2020 Accepted: 9 February 2021

Published online: 12 April 2021

\section{References}

1. Mohd Affandi A, Khan I, Ngah SN. Epidemiology and clinical features of adult patients with psoriasis in Malaysia: 10-year review from the Malaysian psoriasis registry (2007-2016). Stucker M, editor. Dermatol Res Pract. 2018; 2018:4371471. https://doi.org/10.1155/2018/4371471.

2. Gladman DD, Ang M, Su L, Tom BDM, Schentag CT, Farewell VT. Cardiovascular morbidity in psoriatic arthritis. Ann Rheum Dis. 2009;68(7): $1131-5$.

3. Silvestre Salvador JF, Romero-Pérez D, Encabo-Durán B. Atopic dermatitis in adults: A diagnostic challenge. J Investig Allergol Clin Immunol. 2017;27(2): 78-88.

4. Ankad B, Koti V. Dermoscopic approach to inflammatory lesions in skin of color. Clin Dermatol Rev. 2020;4(2):74-8 Available from: https://www.cdria dvlkn.org/article.asp?issn=2542-551X.

5. Huang W, Ahn C. General dermatology. In: Clinical Manual of Dermatology; 2020. p. 31-152.
6. Lee MR, Shumack S. Prurigo nodularis: A review. Australas J Dermatol. 2005; 46(4):211-20. https://doi.org/10.1111/j.1440-0960.2005.00187x.

7. Kharghoria G, Grover C, Bhattacharya SN, Sharma S. Histopathological evaluation of nail lichen planus: A cross-sectional study. J Cutan Pathol. 2021;48(1):11-7. https://doi.org/10.1111/cup.13783.

8. Jain S, Basavaraj V. Direct immunofluorescence studies in Lichen Planus. Turk Patoloji Derg. 2019;35(3):193-7.

9. Reszke R, Białynicki-Birula R, Szepietowski JC. Itch in psoriasis: A new look at well- known subject. Acta Derm Venereol. 2019;99(4):429-34.

10. Szepietowski JC, Reich A. Pruritus in psoriasis: An update. Eur J Pain. 2016; 20(1):41-6. https://doi.org/10.1002/ejp.768.

11. Sarac $G$, Koca $T$, Baglan $T$. A brief summary of clinical types of psoriasis. North Clin Istanbul. 2016:3(1):79-82

12. Sobolewski P, Walecka I, Dopytalska K. Nail involvement in psoriatic arthritis. Reumatologia. 2017:55(3):131-5.

13. de Berker DAR, Richert B, Baran R. Acquired disorders of the nails and Nail unit [Internet]. In: Rook's textbook of dermatology, ninth edition; 2016. p. 176. (major reference works). Available from. https://doi.org/10.1002/978111 8441213.rtd0096.

14. El-Domyati M, Abdel-Wahab H, Abdel-Azim E. Nail changes and disorders in elderly Egyptians. J Cosmet Dermatol. 2014;13(4):269-76. https://doi.org/1 $0.1111 /$ jocd.12113.

15. Zhang W, Doherty M, Leeb BF, Alekseeva L, Arden NK, Bijlsma JW, et al. EULAR evidence-based recommendations for the diagnosis of hand osteoarthritis: report of a task force of ESCISIT. Ann Rheum Dis. 2009;68(1):8-17.

16. Gutte RM. Colocalization of linear lichen planus and psoriasis vulgaris. Indian Dermatol Online J. 2016;7(5):438-40.

17. Delaney TA, Smith NP. Lichen planus mimicking and coexisting with psoriasis in a black patient. Australas J Dermatol. 1993;34(2):59-62. https:// doi.org/10.1111/j.1440-0960.1993.tb00859.x.

18. Kaliyadan F. The dermoscopic auspitz sign. Indian Dermatol Online J. 2018; 9(4):290-1 Available from: https://www.idoj.in/article.asp?issn=2229-5178

\section{Publisher's Note}

Springer Nature remains neutral with regard to jurisdictional claims in published maps and institutional affiliations.

Ready to submit your research? Choose BMC and benefit from:

- fast, convenient online submission

- thorough peer review by experienced researchers in your field

- rapid publication on acceptance

- support for research data, including large and complex data types

- gold Open Access which fosters wider collaboration and increased citations

- maximum visibility for your research: over $100 \mathrm{M}$ website views per year

At $\mathrm{BMC}$, research is always in progress.

Learn more biomedcentral.com/submissions 